Sanders, M. \& Nathan, H. A. (1959). J. gen. Microbiol. 21, 264-270

\title{
Protozoa as Pharmacological Tools: The Antihistamines
}

\author{
By M. SANDERS AND HELENE A. NATHAN
}

Haskins Laboratories, 305 East 48rd Street, New York 17, New York, U.S.A.

\begin{abstract}
SUMMARY: Two protozoa, Ochromonas malhamensis and Tetrahymena pyriformis, were used to study the mode of action and side effects of three antihistamines: diphenhydramine, tripelennamine and pheniramine. The mode of action was studied by inhibition analysis and the side effects by motility tests. The use of these methods as preliminary screening procedures for new chemotherapeutic agents is discussed.
\end{abstract}

Goals in experimental pharmacology include not only the improvement of existing chemotherapeutic agents, but also the elucidation of the metabolic loci of action of these agents. It is desirable to construct model microbiological systems which would parallel and isolate the key animal reactions without the extraneous variables contributed by the use of higher animals. We report here on a series of protozoon assay methods designed to show with antihistamines drug potency, mode of action, toxicity to the host and side actions.

\section{METHODS}

Tetrahymena pyriformis, a ciliated protozoon which may be grown in defined media and which has an exogenous requirement for histidine, was used for growth and motility studies. The maintenance, inoculation and experimental media were those described by Stokstad, Seaman, Davis \& Hutner (1956).

Ochromonas malhamensis, which also has an exogenous requirement for histidine, was only used for growth experiments. Experiments were done either at $\mathrm{pH} \mathrm{5.0} \mathrm{in} \mathrm{the} \mathrm{medium} \mathrm{given} \mathrm{in} \mathrm{Table} 1$ of Hutner et al. (1957) or at $\mathrm{pH} 7.0$ in the medium given in Table XI of Nathan \& Funk (1959).

In growth experiments, both Tetrahymena pyriformis and Ochromonas malhamensis were allowed to grow until the end of the logarithmic growth phase. Growth was then measured as optical density in a Welch Densichron equipped with red probe. The 'potency' of the drugs was evaluated as degree of growth inhibition. The sites of the biochemical lesions were located by the ability of certain compounds to annul this inhibition.

Diphenhydramine (Benadryl), tripelennamine (Pyribenzamine), and pheniramine (Trimeton), all obtained from commercial sources, were used. These compounds were selected as representative members of the three major classes of antihistamines based on whether carbon, nitrogen, or oxygen serve as the link between the aromatic and aliphatic portions of the antihistamine molecule (Fig. 1). The structural similarity of diphenhydramine to procaine (Fig. 1), which possibly accounts for the former's local anaesthetic properties, suggested procaine as a control for the motility studies.

Two-day log-phase cultures of Tetrahymena pyriformis, which had been 
grown in the defined medium, were used for motility experiments. The organisms were separated from the medium by centrifugation and diluted with $0 \cdot 85 \%$ $(\mathrm{w} / \mathrm{v}) \mathrm{NaCl}$ solution (saline) to yield a suspension with an optical density of about 1.0. Each well of a depression slide contained $0 \cdot 15 \mathrm{ml}$. of this suspension + the experimental compounds (in solution adjusted to $\mathrm{pH} \mathrm{7 \cdot 0)}+$ saline to bring the volume in each well to $1.0 \mathrm{ml}$. The effects of the test compounds on the motility of the organisms in the well were observed by direct microscopic examination. Each motility experiment was continued until the organisms in the well containing the procaine control ceased all motion; see, for example, the duration of the two experiments noted in Table 3.

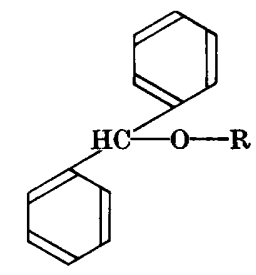

Diphenhydramine

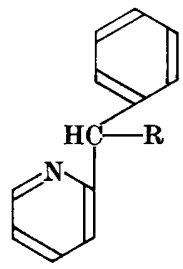

Pheniramine<smiles>[R]N(C)c1ccccn1</smiles>

Tripelennamine<smiles>CN(C)CC=[V]</smiles><smiles>CCCCCCCCCOCc1ccc(N)cc1</smiles>

Procaine

Fig. 1

\section{RESULTS AND DISCUSSION}

The multiplicity of the sites of action of antihistamines has been noted many times. Respirometric and growth experiments on toxicity and the annulment of the toxicity of antihistamines have produced a variety of results, e.g. Landis \& Krops (1951) reported annulment of the fungistatic action of antihistamines on Trichophyton spp. by histamine but not histidine, but Reiss \& Caroline (1955) found that neither histidine nor histamine would annul pheniramine toxicity in Blastomyces sp. Di Ritis \& Zanussi (1949) showed annulment of antihistamine toxicity for bacteria by thiamine + nicotinic acid. Carlisle \& Crescitelli (1950) reported antihistamine inhibition of rat brain cortex respiration when glutamate, but not glucose, served as carbon source. The local anaesthetic effects of antihistamines were reported by Steffen, Zimmerman \& Mihan (1956) and suggested another activity of antihistamines which might be investigated with protozoa.

Our first experiments were done with Ochromonas malhamensis, which has been shown to parallel animal specificity for vitamin $B_{12}$, and, more pertinent to 
these studies, in response to at least one form of stress, namely heat (Hutner et al. 1957). As others have shown that antihistamines are inactive below pH $6 \cdot 8$, possibly from failure of the drugs to penetrate cell membranes because of their ionization state or poor solubility (Jahn \& Danforth, 1952), it was not surprising that when $O$. malhamensis was grown at $\mathrm{pH} 5 \cdot 0$ relatively high concentrations of antihistamines $(0 \cdot 3-1 \cdot 0 \mathrm{mg} . / \mathrm{ml}$.) were needed to inhibit growth. 'Loading' of the system with antihistamines at $\mathrm{pH} 5.0$ obscured the fine biochemical sites of drug action; the inhibition was annulled non-specifically

Table 1. Inhibition of growth* of Ochromonas malhamensis by antihistamines

\begin{tabular}{|c|c|c|c|c|c|c|c|}
\hline & \multicolumn{7}{|c|}{ Drug additions (mg./ml.) } \\
\hline & \multirow[b]{2}{*}{ None } & \multicolumn{2}{|c|}{ Benadryl } & \multicolumn{2}{|c|}{ Pyribenzamine } & \multicolumn{2}{|c|}{ Trimeton } \\
\hline & & 0.003 & 0.01 & 0.003 & 0.03 & $0 \cdot 1$ & 0.3 \\
\hline \multicolumn{8}{|c|}{ I. Additions in $\mu \mathrm{g} . / \mathrm{ml}$. } \\
\hline None & 1.96 & 1.73 & $0 \cdot 22$ & 1.94 & $0 \cdot 13$ & $1 \cdot 15$ & 0.28 \\
\hline DL-Ornithine 0.8 & 1.97 & - & - & $\mathbf{1 . 9 4}$ & $\mathbf{0 . 2 4}$ & 1.06 & 0.64 \\
\hline DL-Ornithine $1 \cdot 0$ & 1.89 & $1 \cdot 52$ & 0.33 & - & - & - & - \\
\hline L-Proline 0.3 & 1.60 & 0.96 & $0 \cdot 49$ & - & - & 1.22 & 0.84 \\
\hline L-Histidine $0 \cdot 3$ & $2 \cdot 00$ & $1 \cdot 68$ & 0.90 & $\mathbf{1 . 9 8}$ & $\mathbf{0} \cdot 42$ & $1 \cdot 41$ & $1 \cdot 27$ \\
\hline L-Histidine $\mathbf{1 \cdot 0}$ & 1.71 & $1 \cdot 50$ & 0.94 & $\mathbf{1 \cdot 6 7}$ & $\mathbf{1} \cdot \mathbf{4 9}$ & $1 \cdot 39$ & $1 \cdot 13$ \\
\hline II. None & $1 \cdot 64$ & 一 & 0.06 & - & $\mathbf{0}$ & 1.85 & - \\
\hline DL-Ornithine $0 \cdot 1$ & 1.79 & - & $\mathbf{0 \cdot 3 0}$ & - & $\mathbf{0 . 3 3}$ & 1.78 & - \\
\hline L-Proline 0.05 & - & - & - & - & - & - & - \\
\hline
\end{tabular}

by carbohydrates, energy-yielding amino acids and metals. This could be used as an indicator of host toxicity induced by drug overdose. The comparison of drug toxicity levels for diphenyramine and tripelennamine at $\mathrm{pH} \mathrm{5.0} \mathrm{(0.3-}$ $1.0 \mathrm{mg} . / \mathrm{ml}$.) and at $\mathrm{pH} 7.0(0.01-0.03 \mathrm{mg} . / \mathrm{ml}$.), where the specific inhibitory sites of the drugs are evident (Table 1 ), gives a rough estimation of the therapeutic index to expect for these drugs. This gross comparison agrees well with the clinical therapeutic indices. The results obtained in the motility experiments used to demonstrate side actions of the drugs also paralleled the degree of clinical side action (drowsiness) of each of these drugs.

The similarity of results obtained with Ochromonas malhamensis grown at pH 7.0 (Table 1) and in growth experiments with Tetrahymena pyriformis (Table 2) indicates that either microbial system may be used to seek evidence for metabolic action sites. In both cases histidine was most active in annulling drug inhibition. Chromatographically pure histamine did not annul drug inhibition. The activity of the impure histamine preparations might be explained by the presence of a histidine contaminant. Ornithine and proline, used singly, were moderately effective in annulling toxicity for both organisms. Together these amino acids were as effective as histidine for $T$. pyriformis (Table 2) but not for 0 . malhamensis. For $T$. pyriformis and for 0 . malhamensis there were some annulment effects by calcium, iron, magnesium and thiamine + nicotinic acid, but these were all less effective than the above amino 
acids. Hydroxyproline, urocanic acid, glutamic acid, tryptophan, alanine and pyridoxamine, all of which are metabolically related to histidine, ornithine and proline, were inactive.

The principal clinical side action of antihistamines, drowsiness, was also studied microbiologically. The highly motile ciliates have an elementary neuromotor system consisting of a co-ordinating centre from which fibres radiate to different ciliary structures at whose bases are found basal granules to which the 'nerve fibres' are attached (Kudo, 1950). Tetrahymena pyriformis was selected to demonstrate the protozoan version of the soporific and local anaesthetic actions of antihistamines (Table 3).

The clinical observation that, of the three drugs used in our experiments, pheniramine exhibits fewer side effects, was paralleled in our protozoan motility experiments (Table 3). Here the intensity of side effects may be ranged: diphenhydramine $>$ tripelennamine $>$ pheniramine.

Table 2. Inhibition of growth of Tetrahymena pyriformis by tripelennamine

\begin{tabular}{|c|c|c|c|c|c|}
\hline & & Tri & amine & ml.) & \\
\hline & None & 0.005 & 0.01 & 0.0125 & 0.015 \\
\hline [. Additions in $\mu \mathrm{g} . / \mathrm{ml}$. & & & & & \\
\hline $\begin{array}{l}\text { None } \\
\text { DL-Ornithine } 1.0\end{array}$ & $\begin{array}{l}1.58 \\
1 \cdot 58\end{array}$ & $\begin{array}{l}1.35 \\
1 \cdot 62\end{array}$ & $\begin{array}{l}0.04 \\
1 \cdot 23\end{array}$ & $\begin{array}{l}0 \\
\mathbf{0}\end{array}$ & $\begin{array}{l}\mathbf{0} \\
\mathbf{0}\end{array}$ \\
\hline L-Proline 0.05 & $1 \cdot 41$ & $1 \cdot 39$ & 1.47 & 0.21 & $\mathbf{0}$ \\
\hline L-Histidine 0.3 & $1 \cdot 18$ & 1.20 & $1 \cdot 33$ & 0.55 & $\mathbf{0}$ \\
\hline L-Histidine 1.0 & $1 \cdot 25$ & 1.25 & $1 \cdot 01$ & $1 \cdot 00$ & $1 \cdot 14$ \\
\hline $\left.\begin{array}{l}\text { L-Proline } 0.05 \\
+ \text { DL-Ornithine } 1.0\end{array}\right\}$ & 1.58 & 1.53 & $1 \cdot 66$ & $1 \cdot 45$ & 1.24 \\
\hline
\end{tabular}

* Results with diphenhydramine and pheniramine essentially the same.

Table 3. Effect of antihistamines and of procaine on the motility of Tetrahymena pyriformis

Experiment 1

(1) Additions in $\mathrm{mg} . / \mathrm{ml}$.

No additions

Glucose 2.0

L-Histidine $\mathbf{2 \cdot 0}$

(2) Procaine 2.5 plus No further additions Glucose 2.0 L-Histidine $2 \cdot 0$

(3) Diphenhydramine 0.25 plus No further additions Glucose $\mathbf{2 \cdot 0}$ L-Histidine $2 \cdot 0$

Elapsed time (min.)

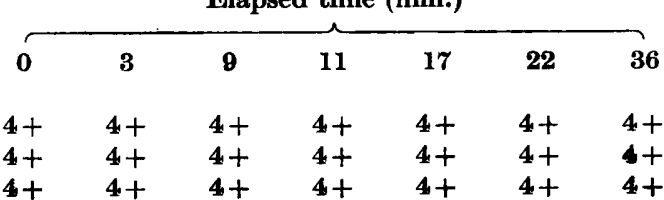

(4) Tripelennamine 0.25 plus No further additions Glucose 2.0 L-Histidine 2.0

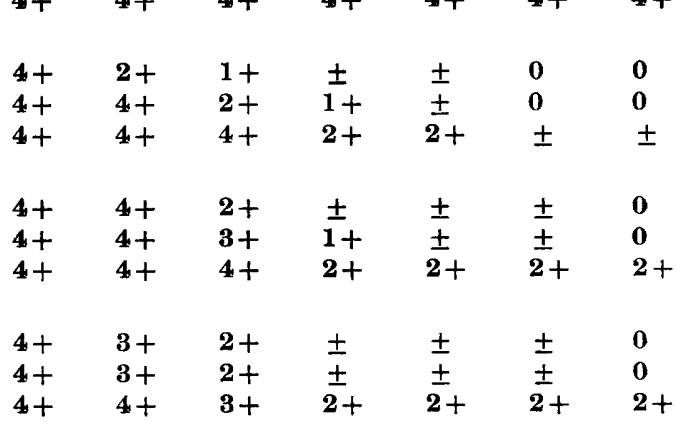


(1) Additions (mg./ml.)

No additions

Glucose 10.0

L-Histidine $5 \cdot 0$

Glucose $10 \cdot 0+\mathrm{L}-\mathrm{Histidine}$ $\mathbf{5} \cdot \mathbf{0}$

Table 3 (cont.)

Experiment 2

Elapsed time (min.)

$\begin{array}{lll}3 & 53 & 106 \\ 4+ & 4+ & 4+ \\ 4+ & 4+ & 3+ \\ 4+ & 4+ & 3+ \\ 4+ & 4+ & 4+\end{array}$

Procaine (mg./ml.)

(2) No additions

Glucose 10.0

L-Histidine $5 \cdot 0$

Glucose $10 \cdot 0+$ L-Histidine $5 \cdot 0$

\begin{tabular}{|c|c|c|c|c|c|}
\hline \multicolumn{6}{|c|}{ Procaine (mg./ml.) } \\
\hline 0.5 & $5 \cdot 0$ & $0 \cdot 5$ & $\mathbf{5} \cdot \mathbf{0}$ & 0.5 & $5 \cdot 0$ \\
\hline $4+$ & $\mathbf{3 +}$ & $\mathbf{3}+$ & $1+$ & $\mathbf{1}+$ & $\mathbf{0}$ \\
\hline $4+$ & $2+$ & $3+$ & \pm & $2+$ & $\mathbf{0}$ \\
\hline $4+$ & $4+$ & $3+$ & $\overline{3}+$ & $2+$ & $2+$ \\
\hline $4+$ & $4+$ & $3+$ & $2+$ & $3+$ & $2+$ \\
\hline
\end{tabular}

(3) No additions

Glucose 10.0

L-Histidine 5.0

Glucose $\mathbf{1 0} \cdot \mathbf{0}+\mathrm{L}$-Histidine $\mathbf{5} \cdot \mathbf{0}$

Diphenhydramine (mg./ml.)

$\begin{array}{llllll}\text { 0.1 } & \mathbf{0 . 3} & \mathbf{0 . 1} & \mathbf{0 \cdot 3} & \mathbf{0 \cdot 1} & \mathbf{0 \cdot 3} \\ \mathbf{4}+ & \mathbf{4}+ & \mathbf{3}+ & \mathbf{1}+ & \mathbf{2}+ & \mathbf{\pm} \\ \mathbf{4}+ & \mathbf{3}+ & \mathbf{2}+ & \mathbf{2}+ & \mathbf{2}+ & \mathbf{1}+ \\ \mathbf{4}+ & \mathbf{4}+ & \mathbf{3}+ & \mathbf{3}+ & \mathbf{3}+ & \mathbf{2}+ \\ \mathbf{4}+ & \mathbf{4}+ & \mathbf{3}+ & \mathbf{2}+ & \mathbf{3}+ & \mathbf{2}+\end{array}$

(4) No additions

Glucose $10 \cdot 0$

L-Histidine $5 \cdot 0$

Glucose $\mathbf{1 0} \cdot \mathbf{0}+\mathrm{L}$-Histidine $\mathbf{5} \cdot 0$

Tripelennamine (mg./ml.)

$\begin{array}{cccccc}\mathbf{0} \cdot \mathbf{1} & \mathbf{0 . 3} & \mathbf{0} \cdot \mathbf{1} & \mathbf{0 \cdot 3} & \mathbf{0 \cdot 1} & \mathbf{0 \cdot 3} \\ \mathbf{4}+ & \mathbf{4}+ & \mathbf{3}+ & \mathbf{2}+ & \mathbf{1}+ & \mathbf{1}+ \\ \mathbf{4}+ & \mathbf{4}+ & \mathbf{3}+ & \mathbf{3}+ & \mathbf{2}+ & \mathbf{1}+ \\ \mathbf{4}+ & \mathbf{4}+ & \mathbf{3}+ & \mathbf{4}+ & \mathbf{2}+ & \mathbf{3}+ \\ \mathbf{4}+ & \mathbf{4}+ & \mathbf{3}+ & \mathbf{3}+ & \mathbf{3}+ & \mathbf{3}+\end{array}$

(5) No additions

Glucose $\mathbf{1 0 \cdot 0}$

L-Histidine 5.0

Glucose $10 \cdot 0+$ L-Histidine $5 \cdot 0$

Pheniramine (mg./ml.)

$$
\begin{aligned}
4+ & =\text { No organisms rounded up, most are actively motile. } \\
3+ & =>90 \% \text { of organisms motile, few are rounded up. } \\
2+ & =\mathbf{5 0} \% \text { of organisms motile, } \mathbf{5 0} \% \text { are rounded up. } \\
1+ & =\mathbf{7 5} \% \text { of organisms rounded up, sluggish motility in the rest. } \\
\pm & =\text { all organisms rounded up. } \\
0 & =\text { most organisms exploded, the remainder rounded up. }
\end{aligned}
$$

Histidine was most effective in maintaining motility in the presence of the antihistamines (Table 3). Glucose, a non-specific substrate control, had slight activity alone and did not significantly enhance the effectiveness of histidine. The histidine-contaminated histamine partially maintained motility in the presence of pheniramine and tripelennamine but was inactive in annulling the effects of procaine or diphenhydramine, probably because there was only enough histidine present (as contaminant) to counteract the compounds which had weak anti-motility action. In the growth and the motility experi- 
ments, diphenhydramine and tripelennamine were $c .5$ times as active as procaine in the motility experiments. Pheniramine was considerably less inhibitory than diphenhydramine or tripelennamine in growth and in motility experiments. The efficacy of histidine in annulling antihistamine inhibition suggests that it is biochemically close to the 'active' material whose metabolism is blocked by the antihistamine. That this same 'active' substance is involved in nerve conduction is implied by the work of Crescitelli \& Geissman (1951) which demonstrated an antihistamine produced conduction block in frog sciatic nerve and by the results of our motility studies with Tetrahymena pyriformis. It is not yet possible to separate the role that histidine may play in nerve conduction, as a metabolic intermediate, and as a metal chelator; indeed there may be some overlap. As known intermediates in the pathway between histidine, ornithine, and proline were inactive in annulling antihistamine growth-inhibition, another, as yet undescribed metabolic connexion among these three may explain their activity.

The histamine which is bound in mammalian tissues is formed from L-histidine but Schayer (1956) noted that it has never been possible to demonstrate binding of exogenous histamine in intact animals. The lack of activity of histamine in our experiments may be a reflection of the inability of the protozoon, like the mammal, to metabolize exogenous histamine.

By combining the results of our growth and motility experiments, it should be possible to suggest that an antihistamine in which the side chain is attached to the aromatic nucleus via a carbon link rather than an ether link would be low in soporific action and that small alterations in this molecule might produce a more effective antihistamine with minimal side effects. In addition, the anti-motility effects observed were quantitatively similar both to the soporific side effects and the local anaesthetic properties of the antihistamines in humans. An approximate margin of safety (therapeutic index) and even a specific antidote might also be suggested. While the efficacy of these antihistamines in annulling growth inhibition was not quantitatively analogous to the efficacy in human beings, the final test for all pharmacological agents must be clinical trial, and, in this respect, the system shares the shortcomings of other preclinical methods.

\section{REFERENCES}

Carlisle, E. M. \& Crescitelli, F. (1950). Selective inhibition of brain respiration by Benadryl. Science, 112, 272.

Crescitelui, F. \& Geissman, T. A. (1951). Certain effects of antihistamines and related compounds on frog nerve fibers. Amer. J. Physiol. 164, 509.

Hutner, S. H., Baker, H., Aaronson, S., Nathan, H. A., Rodriquez, E., Lockwood, S., Sanders, M. \& Peterson, R. A. (1957). Growing Ochromonas malhamensis above $35^{\circ}$ C. J. Protozool. 4, 259.

JAHN, T. L. \& DANFORTH, W. (1952). Inhibition of growth of a green flagellate by the antihistamine Benadryl. Proc. Soc. exp. Biol., N.Y. 80, 13.

Kudo, R. R. (1950). Protozoology. Philadelphia: C. C. Thomas.

LANDIS, L. \& KROPS, S. (1951). Influence of histamine upon the fungistatic action of antihistamines. Proc. Soc. exp. Biol., N.Y. 76, 538. 
Nathan, H. A. \& FunK, H. B. (1959). Relationship between pteridines and other heterocycles (Purines, riboflavin, and vitamin $\mathbf{B}_{12}$ ). Amer. J. Clin. Nutr. (in the Press).

Rerss, F. \& Caroline, L. (1955). Studies with B. dermitidis growth inhibitors. A.M.A. Arch. Derm. 71, 500.

Di Ritis, F. \& Zanussi, C. (1949). Attivita antimicrobica di un anti-istaminico sintetico ( $N$-dimetilaminoetil - $N$-benzilanilina). Riv. 1st Sieroter. ital. 24, 10.

Schayer, R. W. (1956). The origin and fate of histamine in the body. Histamine. London: J. and A. Churchill Ltd.

Steffen, C. G., Zimmerman, M., Mihan, R. (1956). Diphenhydramine hydrochloride as a local anesthetic agent. A.M.A. Arch. Derm. 74, 76.

Stokstad, E. L. R., Skaman, G. R., Davis, R. J. \& Hutner, S. H. (1956). Assay of thioctic acid. Meth. Biochem. Anal. 3, 23.

(Received 26 February 1959) 